Sādhanā Vol. 39, Part 3, June 2014, pp. 677-697. (C) Indian Academy of Sciences

\title{
Elastic properties of RCC under flexural loading-experimental and analytical approach
}

\author{
S K KULKARNI*，M R SHIYEKAR，S M SHIYEKAR and \\ B WAGH
}

Sinhgad College of Engineering, Pune, India

e-mail: sumantk4@yahoo.co.in; mukundshiyekar@gmail.com;

shiyekar@gmail.com; bharatwagh@gmail.com

MS received 4 May 2013; revised 30 January 2014; accepted 2 February 2014

\begin{abstract}
In structural analysis, especially in indeterminate structures, it becomes essential to know material and geometrical properties of members. The codal provisions recommend elastic properties of concrete and steel and these are fairly accurate enough. The stress-strain curve for concrete cylinder or a cube specimen is plotted. The slope of this curve is modulus of elasticity of plain concrete. Another method of determining modulus of elasticity of concrete is by flexural test of a beam specimen. The modulus of elasticity most commonly used for concrete is secant modulus. The modulus of elasticity of steel is obtained by performing a tension test of steel bar. While performing analysis by any software for high rise building, cross area of plain concrete is taken into consideration whereas effects of reinforcement bars and concrete confined by stirrups are neglected. The aim of study is to determine elastic properties of reinforced cement concrete material. Two important stiffness properties such as AE and EI play important role in analysis of high rise RCC building idealized as plane frame. The experimental programme consists of testing of beams (model size $150 \times 150 \times 700 \mathrm{~mm}$ ) with percentage of reinforcement varying from 0.54 to $1.63 \%$. The experimental results are verified by using $3 \mathrm{D}$ finite element techniques. This study refers to the effect of variation of percentage of main longitudinal reinforcement and concrete grade. Effect of confinement is not considered and it appears in a separate study.
\end{abstract}

Keywords. Indeterminate structures; elastic properties; stiffness properties.

\section{Introduction}

In order to design an RC structural element, it is important to gain a general overview of reinforced concrete structures and an understanding of the basic material properties. It is also important to get acquainted with the basic concepts relating to performance criteria in reinforced

*For correspondence 
concrete design. The aim of structural design is to design a structure so that it fulfils three criteria; namely safety in terms of strength, stability and structural integrity, adequate serviceability in terms of stiffness, durability, deformation and economy. The behaviour of section at various stages of loading can be studied in two parts i.e., initial un-cracked phase and the ultimate condition at collapse.

For a simply supported beam subjected to gradually increasing load, the applied moment at any section is less than cracking moment $\mathbf{M}_{c r}$ and the maximum tensile stress $f_{c t}$ in the concrete is less than its flexural tensile strength $f_{c r}$. This phase is called the un-cracked phase. In this case, the entire section is effective in resisting the moment. The un-cracked phase reaches its limit when the applied moment $\mathrm{M}$ becomes equal to the cracking moment $\mathrm{M}_{\mathrm{cr}}$. In the stress-strain curve, un-cracked phase falls within the initial linear portion.

As the applied moment exceeds $\mathrm{M}_{\mathrm{cr}}$, the maximum tensile stress in concrete exceeds the flexural tensile strength of concrete and the propagation of crack enhances. The cracks get developed in the bottom fibres of the beam. As the load increases, the cracks get widened and propagate towards the neutral axis. The cracked portion of the concrete becomes ineffective in resisting tensile stress. Hence, the effective concrete section is reduced. For further increment in the applied moment, strain in tension steel increases which results in an upward shift of the neutral axis and ultimately there is an increase in curvature and collapse occurs.

\section{Current codal provisions in IS: $456-2000$}

For the analysis purpose, modular ratio concept makes it possible to transform the composite section into an equivalent homogeneous section made up entirely of one material. The use of transformed section concept may be limited in determining the neutral axis as the centroidal axis of the transformed section. The stress can be computed in transformed section by applying the flexure formula. In this case the second moment of area $I_{g}$ of the transformed section has to be considered.

Applying the concept of transformed section, the area of tension reinforcement steel $A_{s t}$ is transformed into equivalent concrete area as $\left(\mathrm{m} \mathrm{A}_{\mathrm{st}}\right)$. This transformation is valid in reinforced concrete not only for flexural members, but also for members subjected to axial forces.

Considering the current practice of RC design, it is necessary to carry out one more cycle of analysis and design. IS Code specifies E value for plain concrete and not for the composite reinforced concrete. In first cycle, the conventional RC design of element can be carried out. It provides rough estimation of cross sectional dimensions and the area of steel required. Second cycle of analysis can be done with available design from the first cycle. In this second cycle, as steel area is known for both beam and column, it becomes important to make the use of this steel area in defining effective area of cross section as well as effective moment of inertia considering the amount of steel. Further, there exists two parts in the analysis i.e., pre-cracking and postcracking of RC members. For this, in each case, one should know the material and geometrical properties such as E, A and I for RCC section. Present analysis considers the ductility of RC elements which is due to specified percentage of minimum and maximum reinforcement by IS: 456-2000.

\section{Rationale and significance of the study}

In structural analysis, especially in indeterminate structures, it becomes essential to know material and geometrical properties of members. The IS codal provisions recommend elastic 
properties of concrete and steel and these are fairly accurate enough. These elastic properties are known independently for concrete and steel. But reinforced concrete is a composite material containing steel and concrete. While performing analysis by any software for high rise building, cross area of plain concrete is taken into consideration whereas effects of reinforcement bars and concrete confined by stirrups are neglected. The aim of the present study is to determine elastic properties of reinforced cement concrete material. Two important stiffness properties such as $\mathrm{AE}$ and EI play important role in analysis of high rise RCC building idealized as plane frame. It is also hoped that knowing exact material and geometrical properties, analysis may become more accurate and economical design can be achieved. The proposed experimental programme consists of testing of beams (model size $150 \times 150 \times 700 \mathrm{~mm}$ ) with percentage of reinforcement varying from 0.54 to $1.63 \%$. The experimental results have been verified by using $3 \mathrm{D}$ finite element techniques.

\section{Shortcomings of the traditional method of RC design}

In pre-cracked state, area of concrete below neutral axis is to be considered. Hence value of $\mathrm{I}_{\mathrm{g}}$ is known. In post-cracked state, area of concrete below neutral axis is to be ignored. If the cracks developed below neutral axis are within acceptable limits i.e., hairline cracks, then this area should not be ignored. But if these cracks are wider and deeper, then question arises to what limit for depth and width of cracks is to be considered. Another problem is concerned with $\mathrm{E}$ value of RCC. In conventional design, we take into account E value of plain concrete given by IS: 4562000. Beam section is considered to be safe if ultimate moment of resistance $\mathbf{M}_{\mathrm{ur}}$ is greater than or equal to the factored moment $\mathrm{M}_{\mathrm{u}}$. The ductile failure is accepted to be desirable and for this, IS: $456-2000$ recommends $\mathrm{p}_{\mathrm{t}}$ in the range $\left(0.85 \mathrm{bd} / \mathrm{f}_{\mathrm{y}}\right)$ to $0.4 \%$ of $\mathrm{bD}$, where $\mathrm{b}$ is the width of rectangular cross-section, $\mathrm{d}$ and $\mathrm{D}$ are effective and overall depth of section, respectively and $\mathrm{f}_{\mathrm{y}}$ is the yield stress of steel. The excessive cover to the reinforcement causes cracks at the early stages of loading. In over-reinforced sections, the strength requirement may be satisfied but not the ductility requirement. The ductility requirement may be partly satisfied in case of mild steel, even if $\mathrm{x}_{\mathrm{u}}$ slightly exceeds $\mathrm{x}_{\mathrm{umax}}$.

\section{Present state of art}

The study of effects of the design variables (Soroushian et al 1991) on axial/flexural behaviour of reinforced concrete sections was carried out. These factors were concrete compressive strength, steel yield strength, longitudinal steel ratio and lateral confinement of concrete. It was observed that variations in longitudinal steel yield strength have major effects on the flexural strength. This parameter is of major concern in the present study apart from deflection. A critical review of the equations of ACI 318-89 and Canadian standard CAN3-A23.3 was made (Amin Ghali 1993) for the prediction of the immediate and long-term deflection in one-way non-pre-stressed construction. A more accurate approach was proposed which was comparatively easy to apply in practice. The equation for effective moment inertia was replaced by equation for mean curvature for use in deflection calculation of a cracked section. The three equations were proposed applicable to un-cracked and cracked sections by using the appropriate cross-sectional area properties. Similar expressions were proposed (Khuntia \& Ghosh 2004a) for computation of moments of inertia of beams and columns. The authors also explained the need for modifications to the ACI codal provisions. A companion paper was also published 
(Khuntia \& Ghosh 2004b) emphasizing the applicability of the proposed stiffness expressions for all levels of applied loading, both service and ultimate loads. The parameters of interest were reinforcement ratio, concrete compressive strength, magnitude of axial load and the eccentricity ratio. A non-linear numerical model was developed (Siddique \& Rouf 2006) considering material and geometrical non-linearities. For simulation of material non-linearity, parabolic stress-strain relationship of reinforcing steel and bilinear relationship of reinforcing steel was considered. The modified Newton-Raphson method was used for solution of nonlinear equation. The authors observed from the analyses that for high strength concrete, the increase in steel content increases the strength and stiffness but ductility is decreased. As soon as the cracks get induced in the section, effective moment of inertia is considered instead of gross moment of inertia. Experimental verification of effective moment of inertia was carried out (Akmaluddin \& Thomas 2007) for calculation of RC beam deflection. The beams were subjected to two-point loading with concrete strength and reinforcement ratio as the variables. Out of three models tested, Model 3 only was valid for calculating effective moment of inertia of singly reinforced RC beams. The reinforcement ratio was between $1 \%$ and $3.25 \%$. A procedure was presented for finding the analytical moment curvature behaviour of statically determinate beams (Srikanth et al 2007). The confinement offered by shear reinforcement to concrete in compression zone was taken into consideration. The authors observed that the results obtained from the selected six models were close to experimental values. The spacing and width of cracks are also important while studying the flexural behaviour of RC beams. An empirical procedure was introduced (Amir et al 2013) for determination of crack opening in a reinforced concrete prism. The authors investigated effective parameters and the results were compared with the available experimental data. The parameters considered were bar size and the effective concrete area surrounding the reinforcement. In addition to these parameters, the additional parameter considered in the present study is grade of concrete.

\section{Experimental work}

In the present study, experimental investigation of the RCC models under flexural loadings is carried out. Possible combinations of reinforcement for flexure test for M20, M25 and M30 grade of concrete are shown in tables 1, 2 and 3, respectively. Model size $150 \times 150 \times 700 \mathrm{~mm}$ is used as per Clause 7.3, IS 516:1959 (Reaffirmed 2004) Methods of Tests for Strength of Concrete.

For each combination, 3 models were tested and average results are presented. IS: 456-2000 recommends minimum area of steel as $(0.85 \%$ of effective area of cross-section $) / f_{y}$ and maximum area of steel $0.4 \%$ of gross area of cross-section. Based on these recommendations, area of steel for various grades of concrete and steel used in experimental programme are given in tables 1,2 and 3 .

Table 1. Combinations of reinforcement for flexure test (M20).

\begin{tabular}{lcccc}
\hline Model no. & Diameter & No. of bars & Area of Tension Steel (sq.mm.) & pt (\%) \\
\hline 1 & - & - & - & 0.00 \\
2 & 8 & 2 & 100.53 & 0.54 \\
3 & $8+6$ & $2+1$ & 128.81 & 0.69 \\
4 & 8 & 3 & 150.79 & 0.80 \\
5 & 10 & 2 & 157.08 & 0.84 \\
\hline
\end{tabular}


Table 2. Combinations of reinforcement for flexure test (M25).

\begin{tabular}{lcccc}
\hline Model no. & Diameter & No. of bars & Area of Tension Steel (sq.mm.) & pt (\%) \\
\hline 1 & - & - & - & 0.00 \\
2 & 8 & 2 & 100.53 & 0.54 \\
3 & $8+6$ & $2+1$ & 128.81 & 0.69 \\
4 & 8 & 3 & 150.79 & 0.80 \\
5 & 10 & 2 & 157.08 & 0.84 \\
6 & 12 & 2 & 226.19 & 1.21 \\
\hline
\end{tabular}

Figure 1 shows the development of crack during the loading. It can be observed from the figure that the crack initiated at an early load for all beam specimens before ultimate failure. The crack has reached approximately one-fourth of the total depth of the beam from bottom. The crack shown in the figure is highlighted with a thin black coloured line.

Figure 2 shows crack pattern at failure for an RC beam specimen. The crack reached more than half the depth of the beam specimen. The PCC beam specimen broke into two pieces at failure. But the entire beam specimens with reinforcement failed with cracks on the surface. However, crack initiation was carefully observed with naked eyes so as to note the corresponding load.

Figure 3 shows a typical RC beam specimen showing shear crack at failure. These beam specimens have been modelled in ANSYS and simulated. The shear failure pattern of the specimen was verified in the FE model of the beam specimen.

\section{Results}

Figure 4 shows load deflection curve for PCC beam specimen of M20 grade of concrete. The specimen failed at a load of $75 \mathrm{kN}$ and first crack developed was at a load of $68.65 \mathrm{kN}$. The corresponding deflection was $0.26 \mathrm{~mm}$. Figures 5 to 8 represent load deflection curve for RCC beam specimen. In these specimens, because of reinforcement, the load at first crack as well as the failure load was observed to be higher and on the other hand, the corresponding deflection was smaller. The deflections measured for all the specimens were mid-span deflections.

Table 3. Combinations of reinforcement for flexure test (M30).

\begin{tabular}{lcccc}
\hline Model no. & Diameter & No. of bars & Area of Tension Steel (sq.mm.) & pt (\%) \\
\hline 1 & - & - & - & 0.00 \\
2 & 8 & 2 & 100.53 & 0.54 \\
3 & $8+6$ & $2+1$ & 128.81 & 0.69 \\
4 & 8 & 3 & 150.79 & 0.80 \\
5 & 10 & 2 & 157.08 & 0.84 \\
6 & 12 & 2 & 226.19 & 1.21 \\
7 & $12+10$ & $2+1$ & 304.73 & 1.63 \\
\hline
\end{tabular}




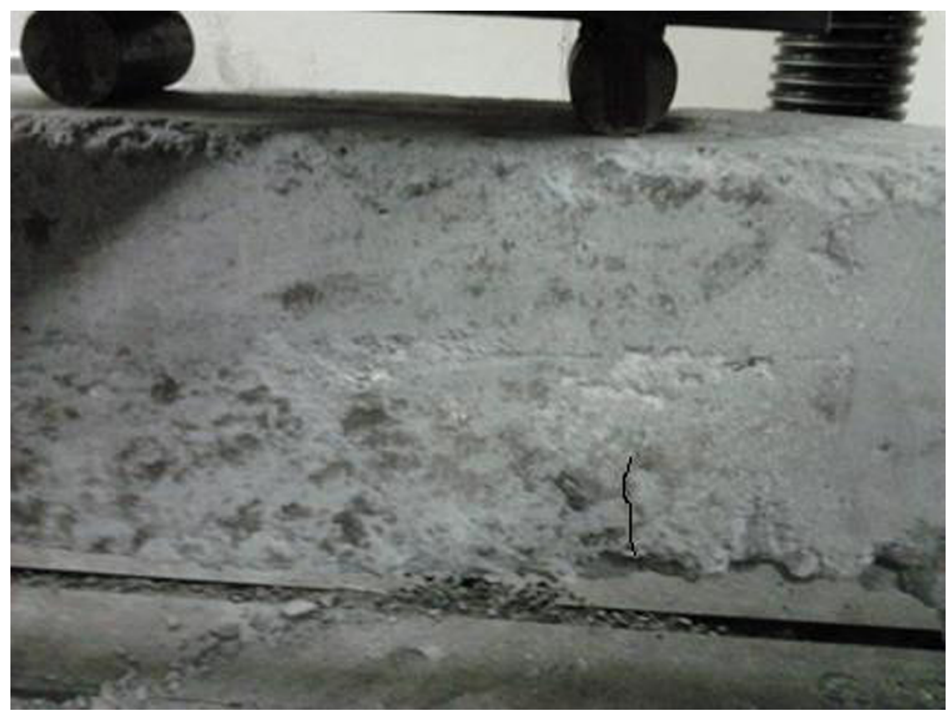

Figure 1. Typical beam specimen showing first crack during loading.

\subsection{Evaluation of $E$ of $R C C$ for M20 grade of concrete}

For a beam subjected to two-point loading the deflection formula is as follows

$$
\delta=\left(\frac{5}{384}\right) \times\left(\frac{w l^{4}}{E I}\right)+\left(\frac{23}{648}\right)\left(\frac{W l^{3}}{E I}\right),
$$

where $w$ is self-weight of beam in $\mathrm{N} / \mathrm{mm}$ and $\mathrm{W}$ is half the load at failure in $\mathrm{N}$.

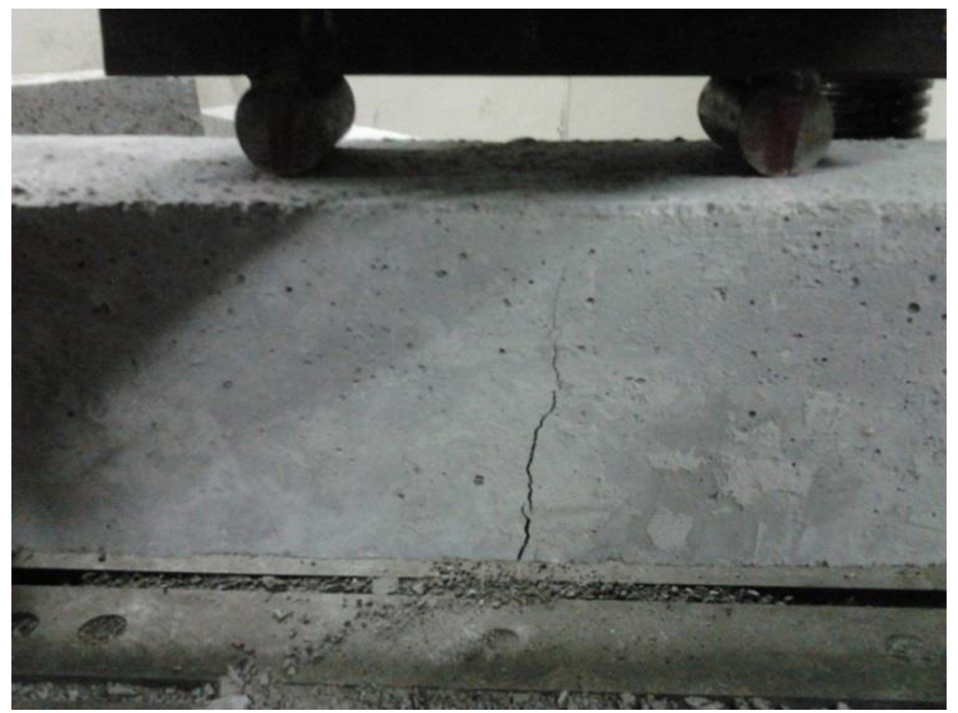

Figure 2. Typical beam specimen showing crack at failure. 


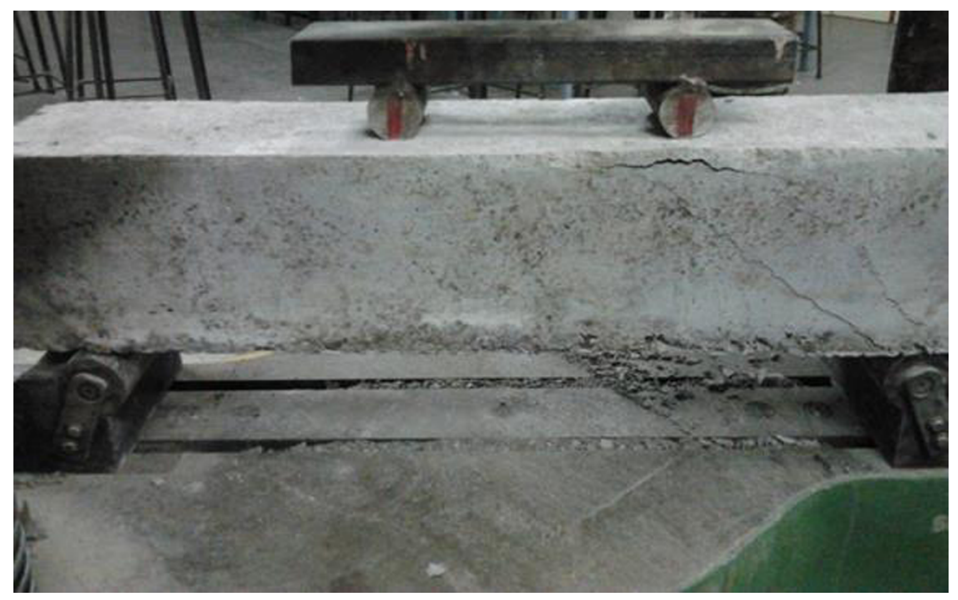

Figure 3. Typical beam specimen showing shear crack at failure.

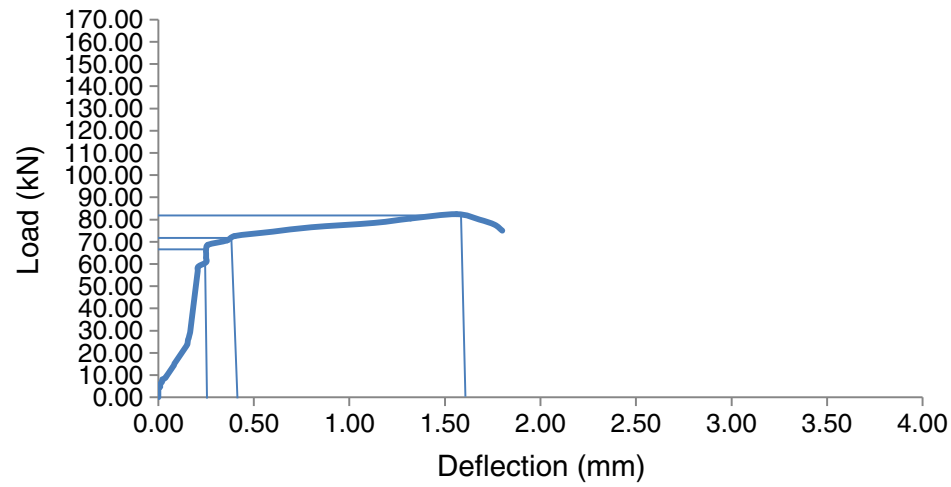

Figure 4. Load deflection curve for model 1 (M20).

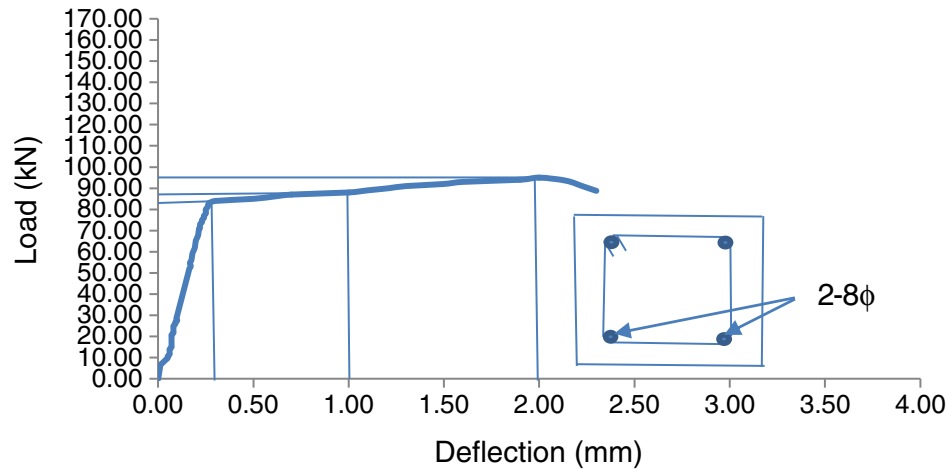

Figure 5. Load deflection curve for model 2 (M20). 


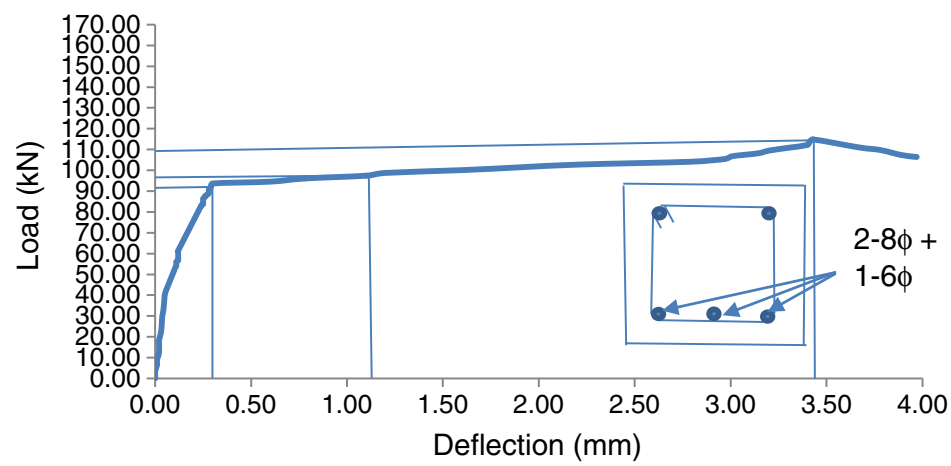

Figure 6. Load deflection curve for model 3 (M20).

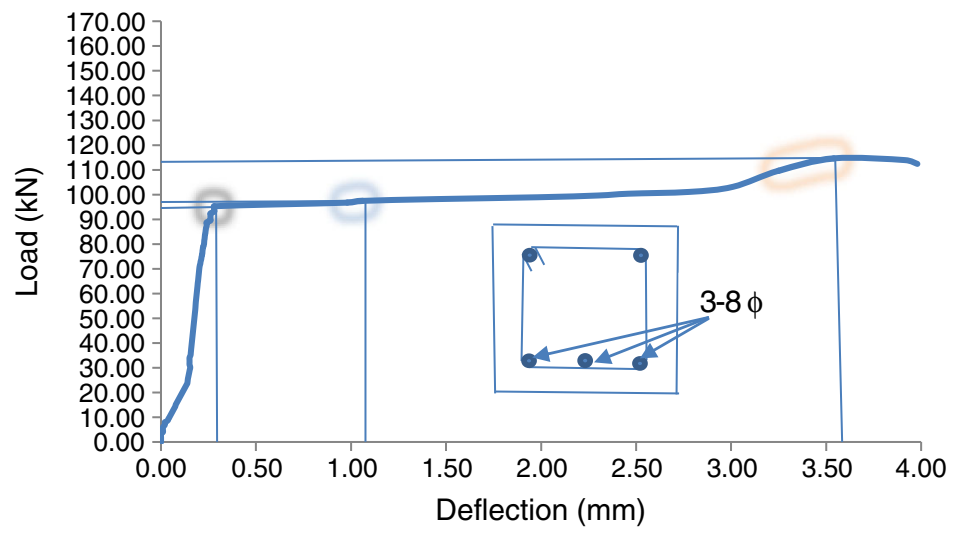

Figure 7. Load deflection curve for model 4 (M20).

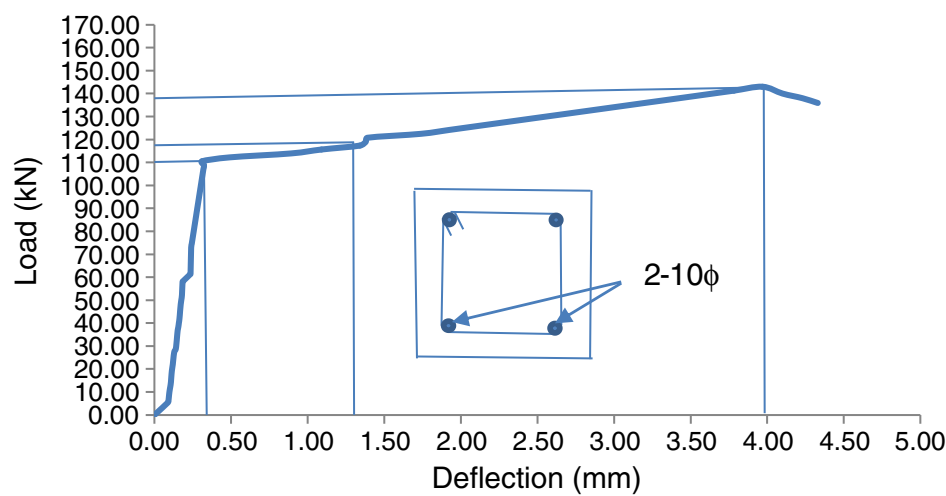

Figure 8. Load deflection curve for model 5 (M20). 
Table 4. Percentage of steel and corresponding E value of RCC (M20).

\begin{tabular}{lcc}
\hline Model no. & Percentage of steel reinforcement $\left(\mathrm{p}_{\mathrm{t}}\right)$ & Modulus of elasticity $\left(\mathrm{N} / \mathrm{mm}^{2}\right)$ \\
\hline 1 & 0.00 & 24066.81 \\
2 & 0.54 & 28288.60 \\
3 & 0.69 & 28453.85 \\
4 & 0.80 & 31013.40 \\
5 & 0.84 & 32478.33 \\
\hline
\end{tabular}

The experimental value of mid-span deflection is substituted in the above equation for each case. By substituting proper values of $\mathrm{w}, \mathrm{W}, l$, and $\mathrm{I}$, the remaining unknown value i.e., $\mathrm{E}$ is evaluated.

Eq. (1) is applicable for linear behaviour only. The value of W substituted in this expression is corresponding to first crack.

Modulus of elasticity of PCC by IS: $456-2000$ formula is $5000 \sqrt{f_{c k}}=5000 \sqrt{20}=$ $22360.68 \mathrm{~N} / \mathrm{mm}^{2}$.

Graphical representation of the values indicated in table 4 is shown in figure 9 . The equation for $\mathrm{E}$ value of RCC from the graph is of the following form Eq. (2) which varies with the percentage of reinforcement.

$$
E_{R C C}=9495.5 p_{t}^{2}+1259.5 p_{t}+24124
$$

\subsection{Evaluation of E of RCC for M25 grade of concrete}

Following graphs and table pertain to test results of RC beam using M25 grade of concrete.

Figures 10-15 are load-deflection curves for M25 grade for all specimens in table 2 . The curve for each specimen is different because of reinforcement. The load at first crack ranges from 62.75 to $144.20 \mathrm{kN}$. The load carrying capacity of the specimens has increased due to increase in the percentage of reinforcement. The same trend was observed for specimens of M30 grade of concrete shown in figures 17-23.

$\mathrm{E}$ of RCC for M25 grade of concrete is also evaluated as per the procedure mentioned above.

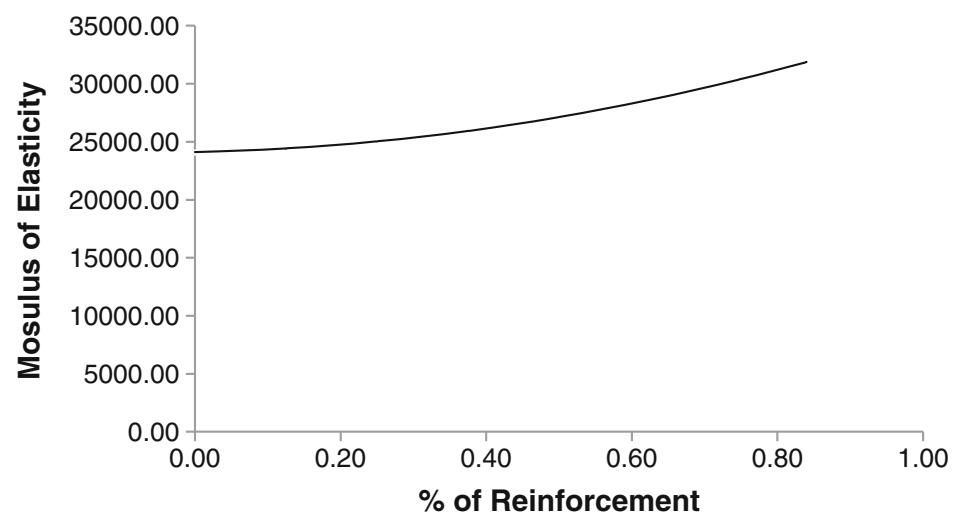

Figure 9. Modulus of elasticity vs \% of reinforcement (M20). 


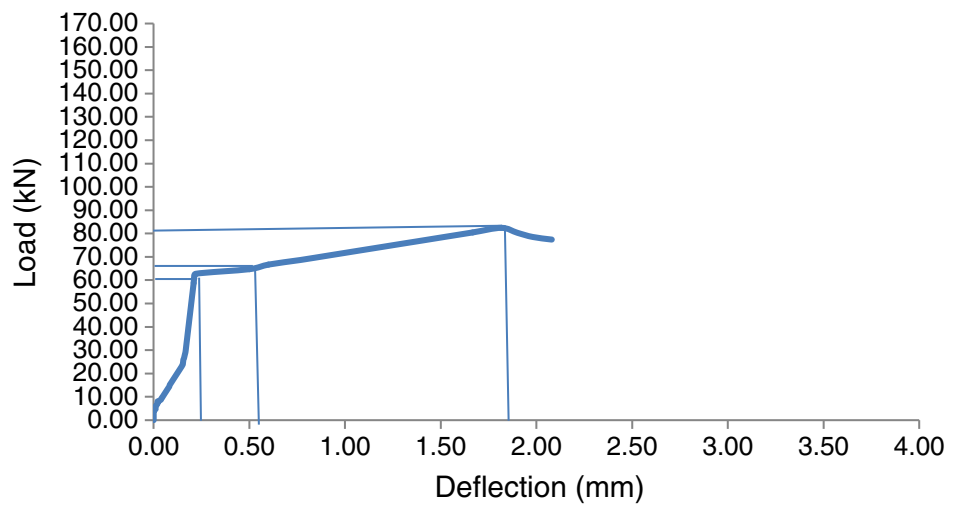

Figure 10. Load deflection curve for model 1 (M25).

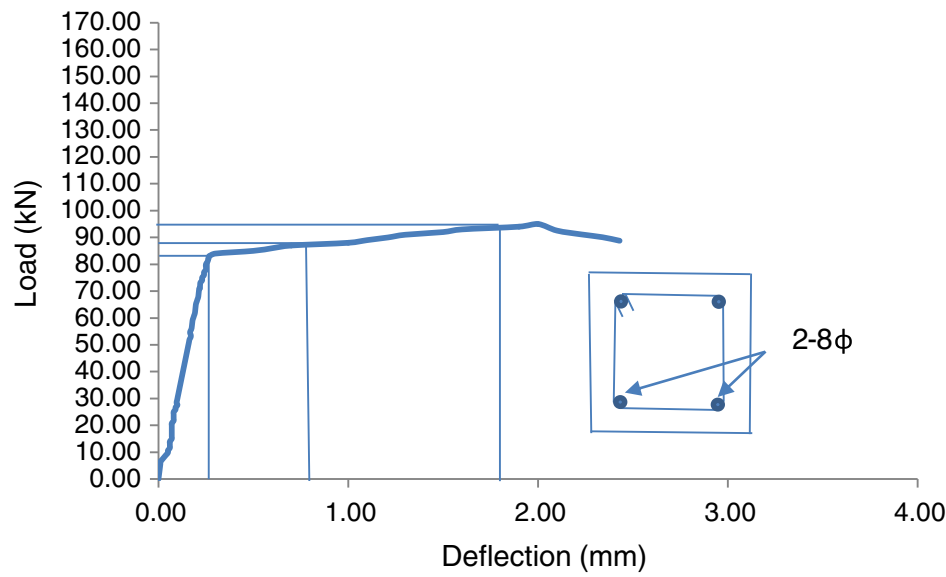

Figure 11. Load deflection curve for model 2 (M25).

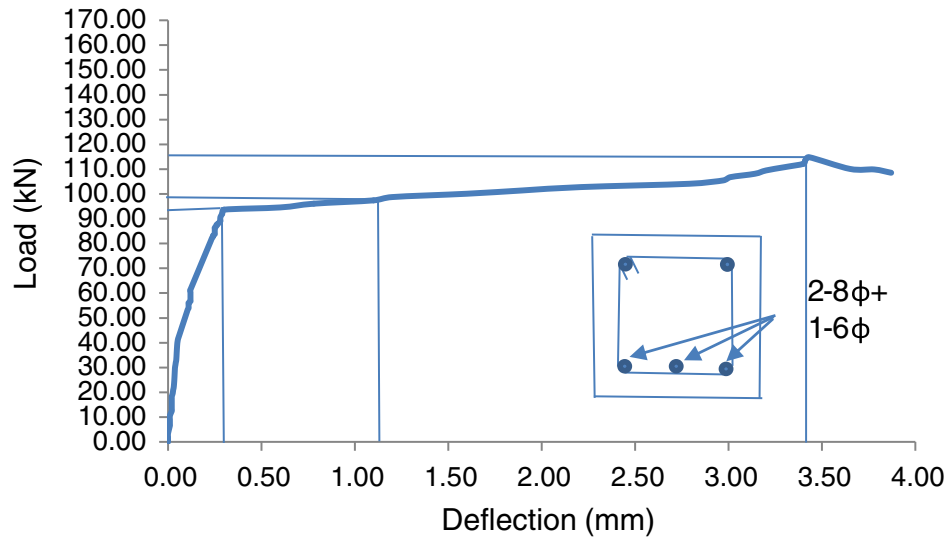

Figure 12. Load deflection curve for model 3 (M25). 


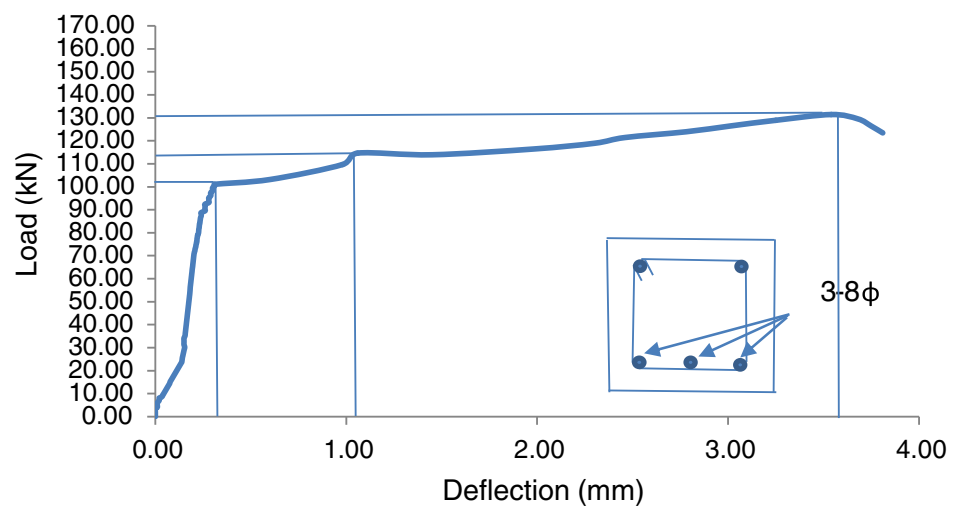

Figure 13. Load deflection curve for model 4 (M25).

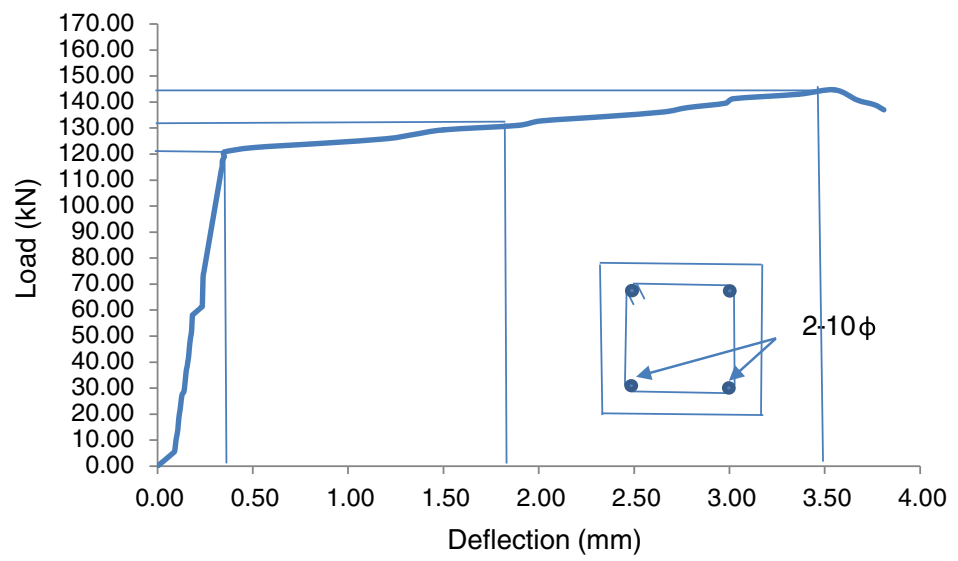

Figure 14. Load deflection curve for model 5 (M25).

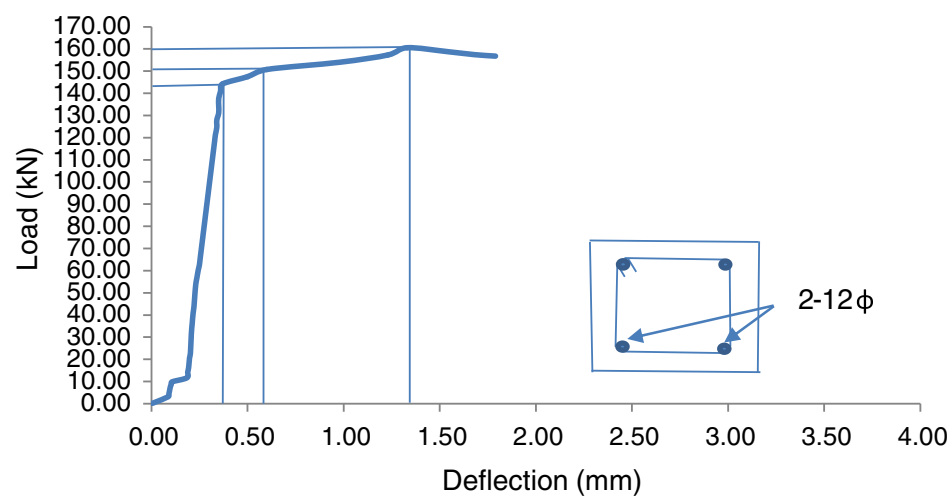

Figure 15. Load deflection curve for model 6 (M25). 


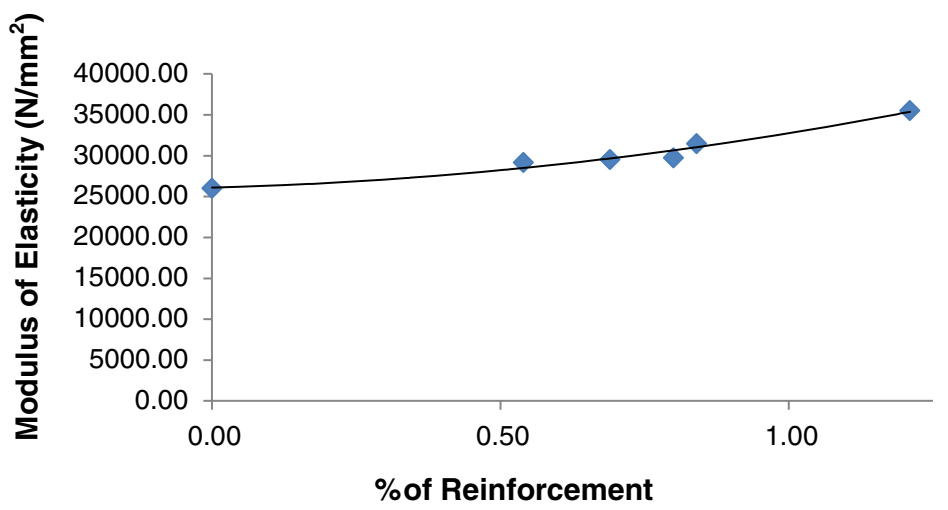

Figure 16. Modulus of elasticity vs \% of reinforcement (M25).

Modulus of elasticity of PCC by IS: $456-2000$ formula is $5000 \sqrt{f_{c k}}=5000 \sqrt{25}=$ $25000 \mathrm{~N} / \mathrm{mm}^{2}$.

The equation for E of RCC from the graph shown in figure 16 is of the following form Eq. (3) which varies with the percentage of reinforcement $\mathrm{p}_{t}$.

$$
E_{R C C}=4813.8 p_{t}^{2}+1840.3 p_{t}+26099 .
$$

\subsection{Evaluation of E of RCC for M30 grade of concrete}

Following graphs and table pertain to test results of RC beam using M30 grade of concrete.

Modulus of elasticity of PCC by IS: $456-2000$ formula is $5000 \sqrt{f_{c k}}=5000 \sqrt{30}=$ $27386.13 \mathrm{~N} / \mathrm{mm}^{2}$.

The equation for E of RCC from the graph shown in figure 24 is of the following form Eq. (4) which varies with the percentage of reinforcement $\mathrm{p}_{\mathrm{t}}$.

$$
E_{R C C}=4813.8 p_{t}^{2}+1840.3 p_{t}+26099 .
$$

Figures 17-23 express the behaviour of RC beam models for M30 grade of concrete. All RC beams showed very less crack development in tension zone. Also, the load carrying capacity of

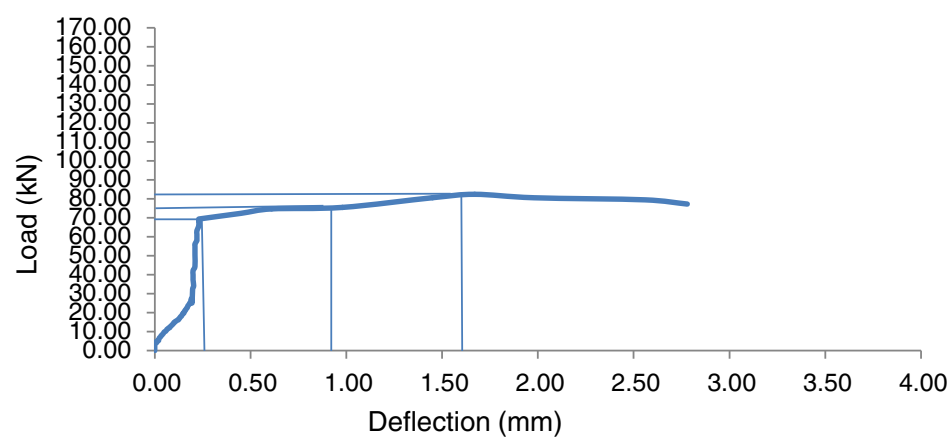

Figure 17. Load deflection curve for model 1 (M30). 


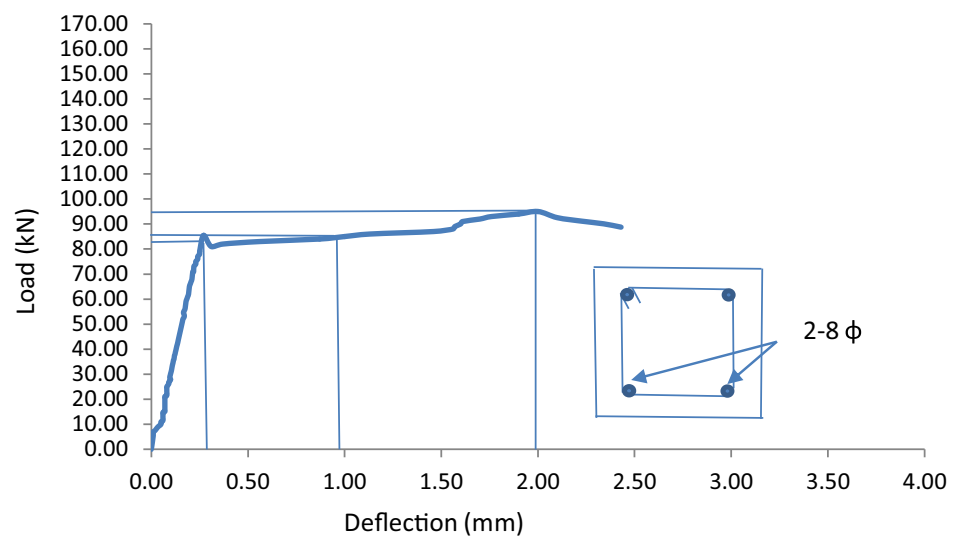

Figure 18. Load deflection curve for model 2 (M30).

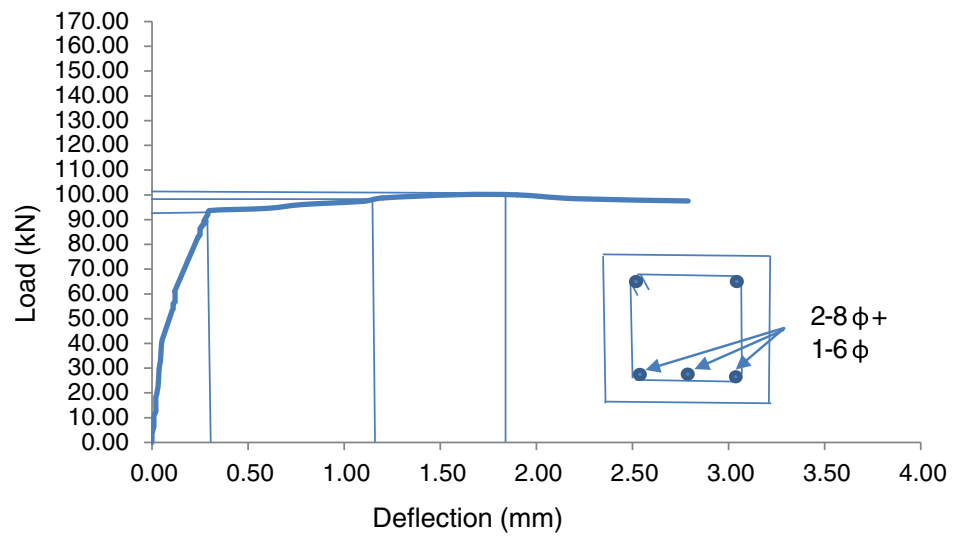

Figure 19. Load deflection curve for model 3 (M30).

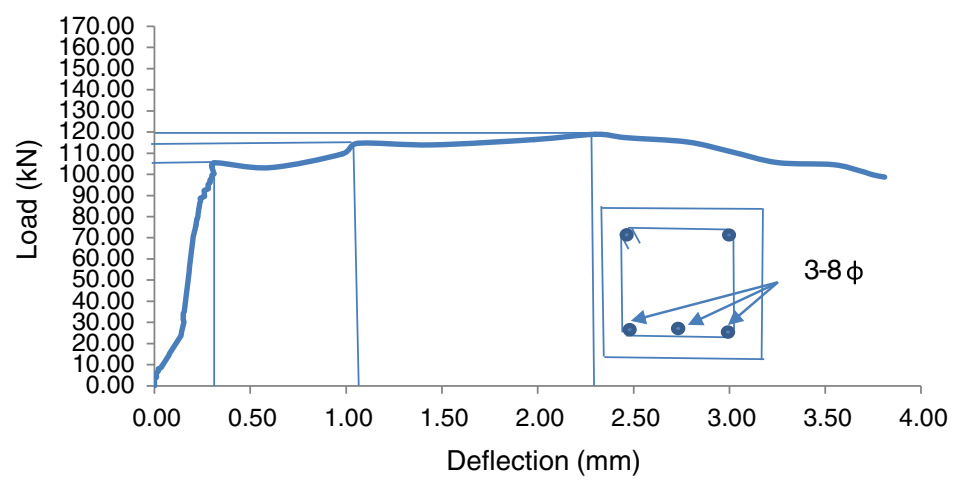

Figure 20. Load deflection curve for model 4 (M30). 


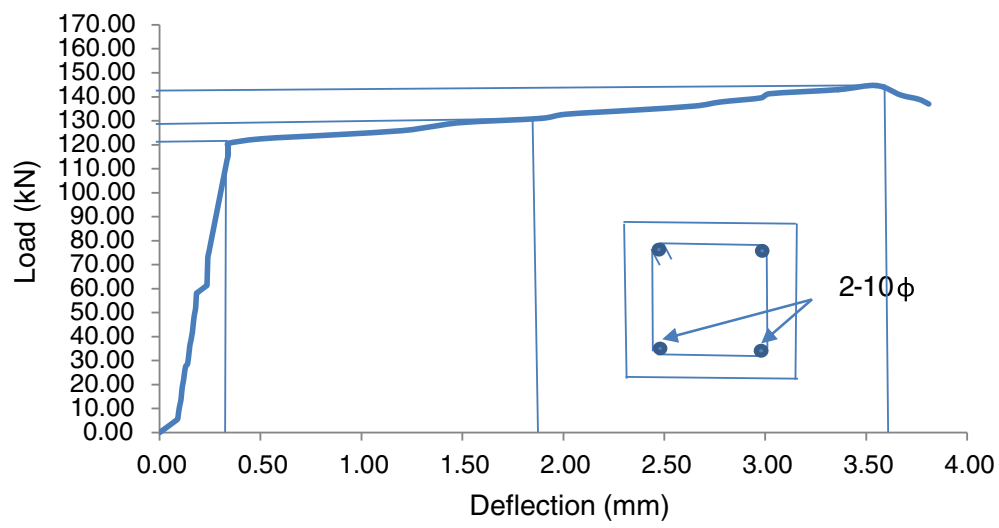

Figure 21. Load deflection curve for model 5 (M30).

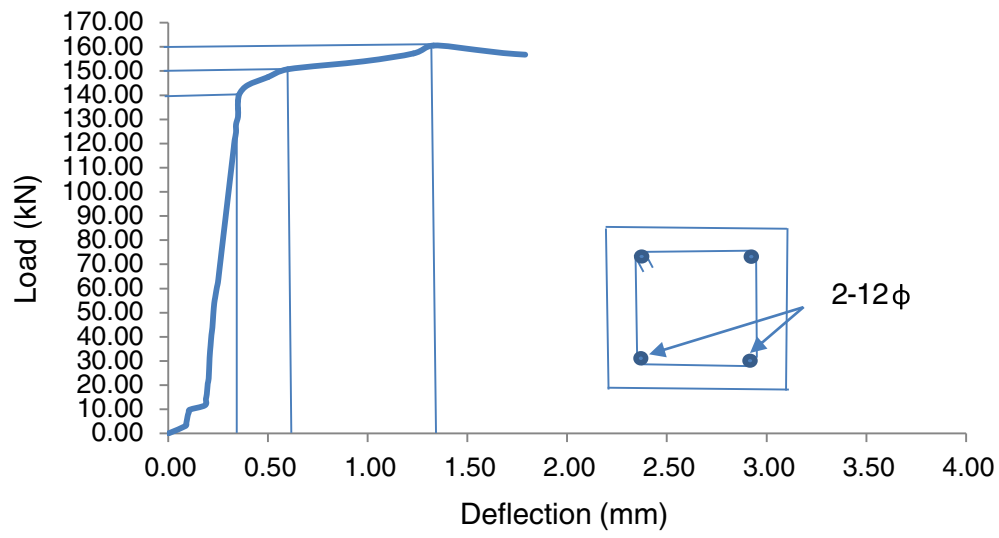

Figure 22. Load deflection curve for model 6 (M30).

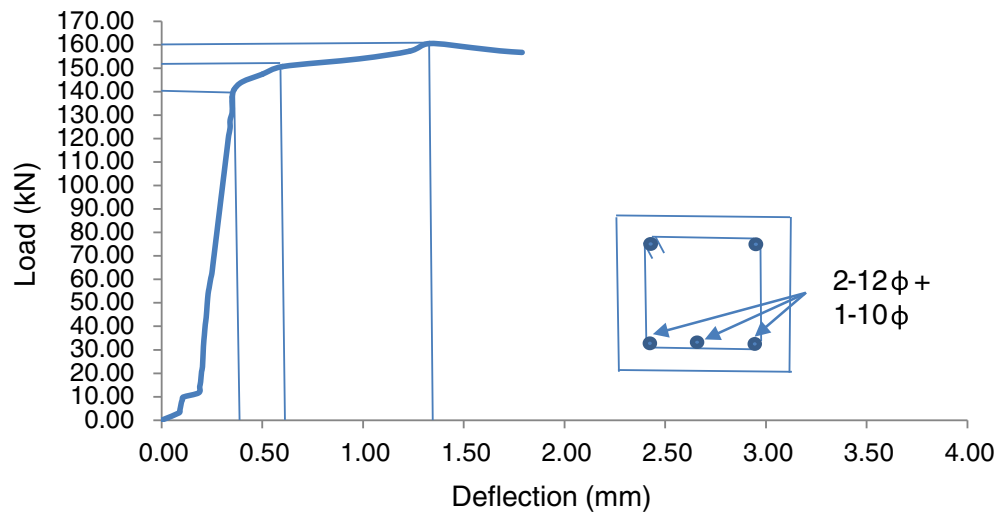

Figure 23. Load deflection curve for model 7 (M30). 


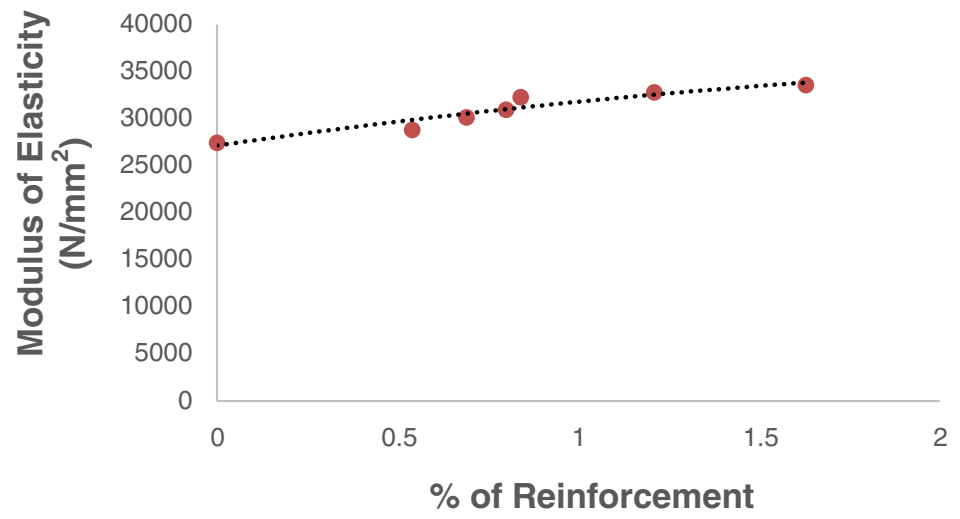

Figure 24. Modulus of elasticity vs \% of reinforcement (M30).

the specimens was highly enhanced due to higher grade of concrete and reinforcement. When the beams reached the limit state, a sufficient time was available before failure. However, an initial softening is observed in all curves except in figures 6, 12 and 19. In all the curves, the reason for this initial softening may be attributed to the bond slip of reinforcement (figure 24).

\section{FE analysis}

In order to get realistic behaviour of RC material analytically, a lot of combinations are required in modelling the beam by ANSYS (Vasudevan \& Kothandaraman 2011). The various parameters which oversee the highly accurate nonlinear behaviour of RC beam are idealization of reinforcement in concrete, constitutive properties of concrete, mesh density, combination of boundary conditions for supports and symmetric planes, incorporation of loading and support areas, influence of shear reinforcement on flexural behaviour, effect of convergence criteria, effect of percentage of reinforcement and many others. Three different uniaxial constituents accomplished of tension and compression only, could be cast-off as a smeared reinforcement, each one in any direction (Antonio \& Gabriel 1998). But it has been observed that for tension reinforcement, finite element meshes with discrete reinforcement are more realistic. The results of the present study are verified with the analytical results.

The realistic and practical modelling of steel and surrounded concrete is one of the most challenging problems in structural analysis. Such a modelling is unavoidable in studying structural behaviour. The grades of concrete selected in the present study are M20, M25 and M30. For concrete, the element used is SOLID65. The element is defined by eight nodes having three degrees of freedom at each node i.e., translation in $\mathrm{x}, \mathrm{y}$, and $\mathrm{z}$ directions. This element is a highly nonlinear element and specifically used for materials like concrete and it takes into account cracking in three orthogonal directions due to tension, compression and plastic deformation. Strain ratio between the concrete and steel is supposed to be equal assuming perfect bond, therefore it is accepted that there is a unique adherence between the concrete and steel. Hence there is no element defined between concrete and steel.

For the main reinforcement and stirrups, LINK8 spar element with three degrees of freedom at each node is used. 


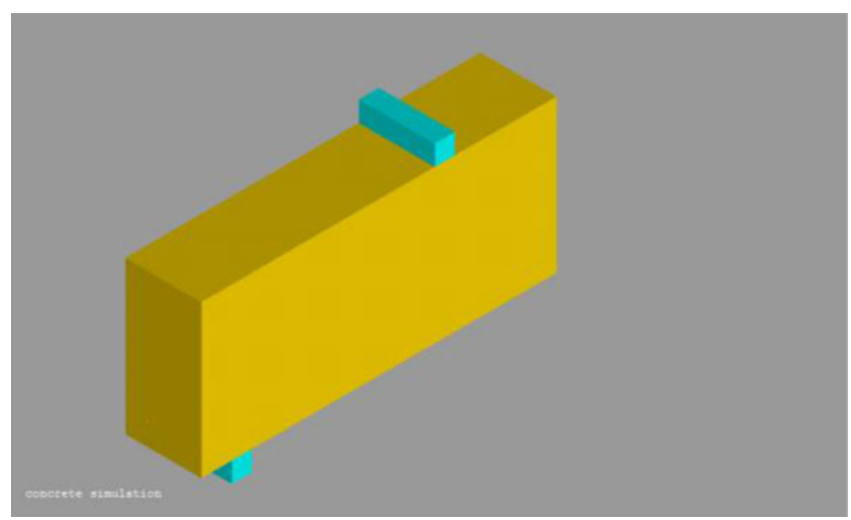

Figure 25. FE model for concrete.

It was observed that the region of load and the supports are facing a problem of stress concentration. Hence in order to arrest this problem, the supports and loading region are modelled with a steel block. The element used for this is SOLID45 with three degrees of freedom $(\mathrm{u}, \mathrm{v}, \mathrm{w})$ at each node. This element is treated as a linear element.

The boundary conditions need to be applied at points of symmetry and where the supports and loading exist (Amer \& Huda 2009). Taking the advantage of symmetry, only one-fourth part of the beam model is considered in the analysis. Figure 25 shows the FE model for concrete. Figure 26 shows FE model for main steel and stirrups. Finite element analysis of deep beams (Patil et al 2012) subjected to two point loading with three different L/D ratios (1.5, 1.6 and 1.71) was carried out. It was observed that for smaller span/depth ratio, the deviation of strain pattern at mid-section of beam was more.

As it is very well-known that concrete is a highly nonlinear material, for accurate modelling in ANSYS-12, there is a provision of multi-linear isotropic hardening constant (MISO). This property has been utilized in this FE model. For the main steel, the bilinear kinetic hardening

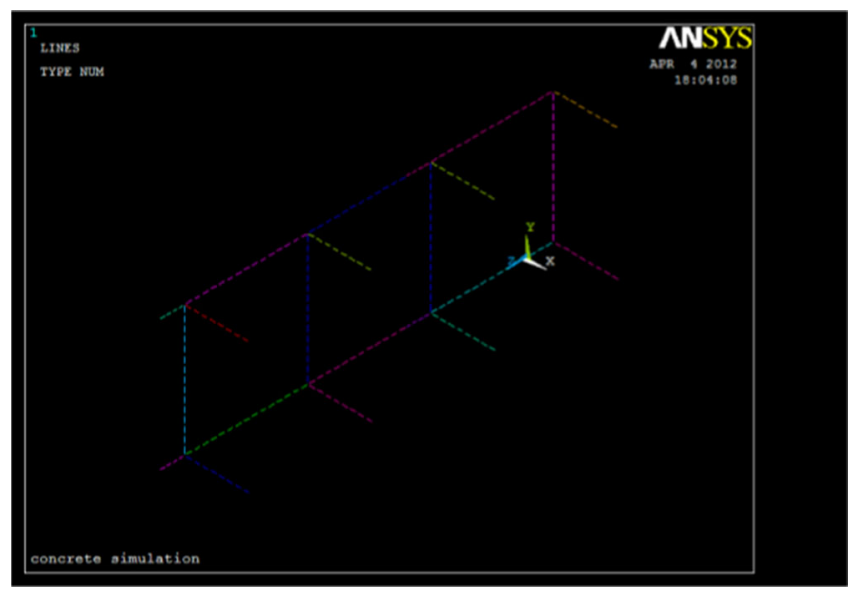

Figure 26. FE model for main steel and stirrups. 


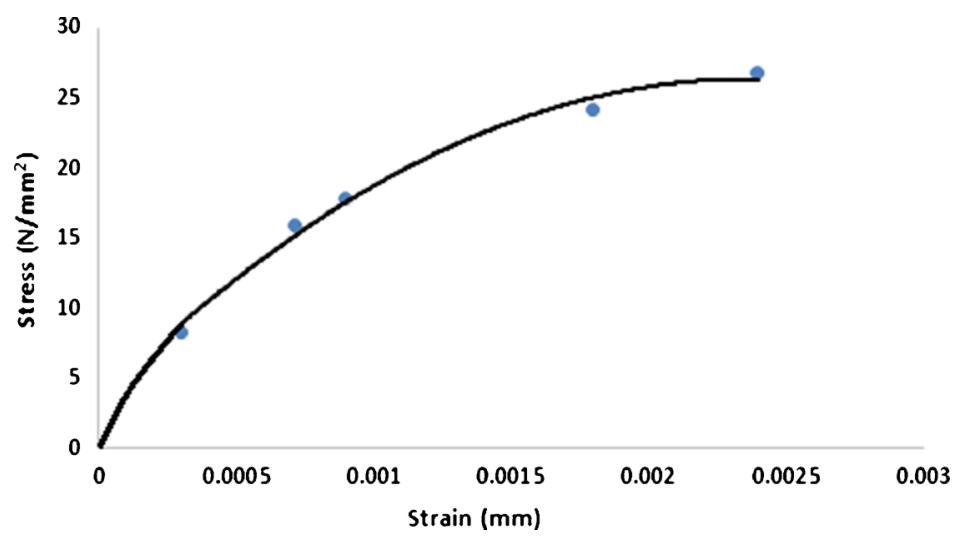

Figure 27. A typical stress-strain curve for model 2 of M20.

constant (BKIN) property has been used. The Bilinear Kinematic Hardening (BKIN) option assumes the total stress range is equal to twice the yield stress. This option is recommended for general small-strain use for materials that obey von Mises yield criteria. The typical MISO and BKIN properties are shown in figures 27 and 28, respectively.

\section{Loading and restraints}

Simply supported beam is chosen for FE model. The support as well as the load has been modelled as a steel block shown in figure 25. The nodes in XY and YZ plane were restrained along $\mathrm{Z}$ and $\mathrm{X}$ axes, respectively. Along the length of the steel block on its top surface, the centre line

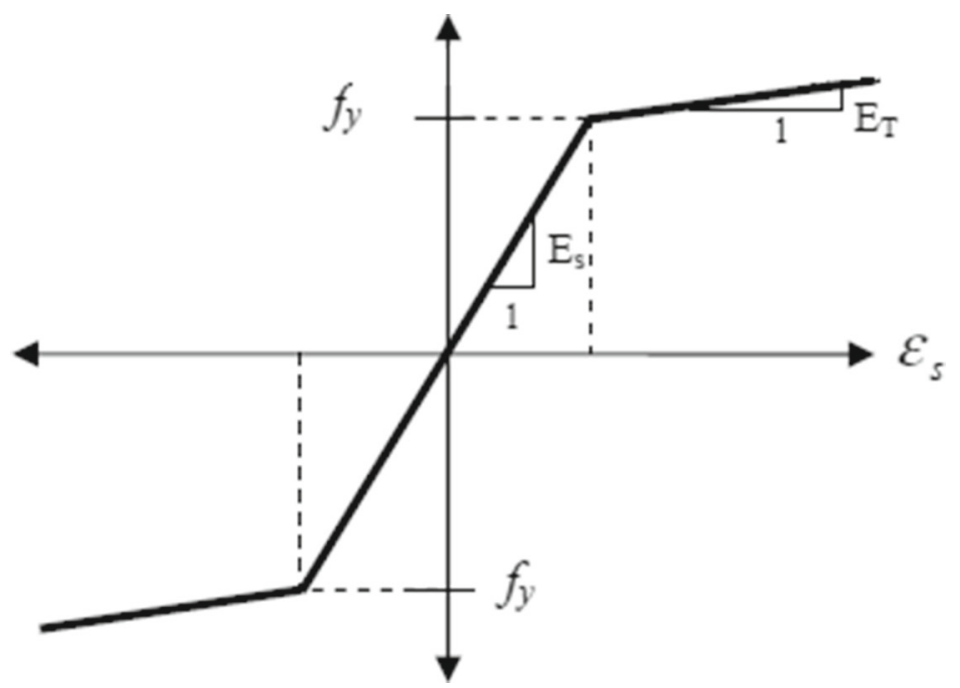

Figure 28. Modelling of reinforcing bar. 


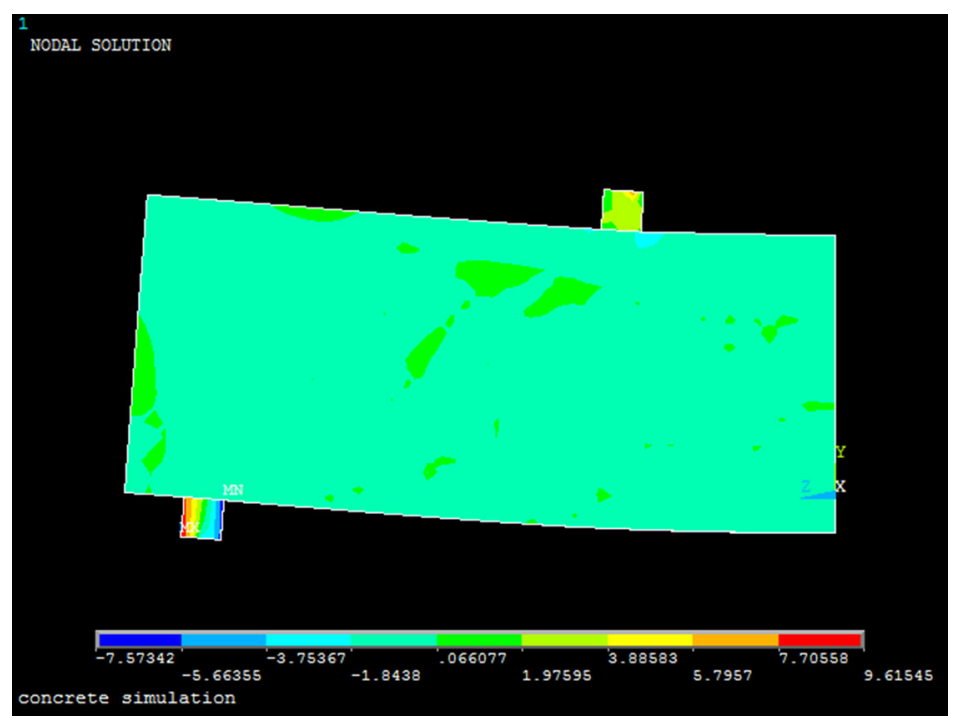

Figure 29. First crack pattern for model 2 of M20 grade of concrete.

nodes are given a deflection observed during the experiment for each specimen. The load corresponding to this deflection is seen in the ANSYS results. It is observed that the experimental load and load from ANSYS was nearly the same.

\section{Results}

ANSYS provided the results like load corresponding to first crack, deflection plot of the model, stresses in $\mathrm{x}, \mathrm{y}$ and $\mathrm{z}$ directions. The results are verified with the experimental investigation. It

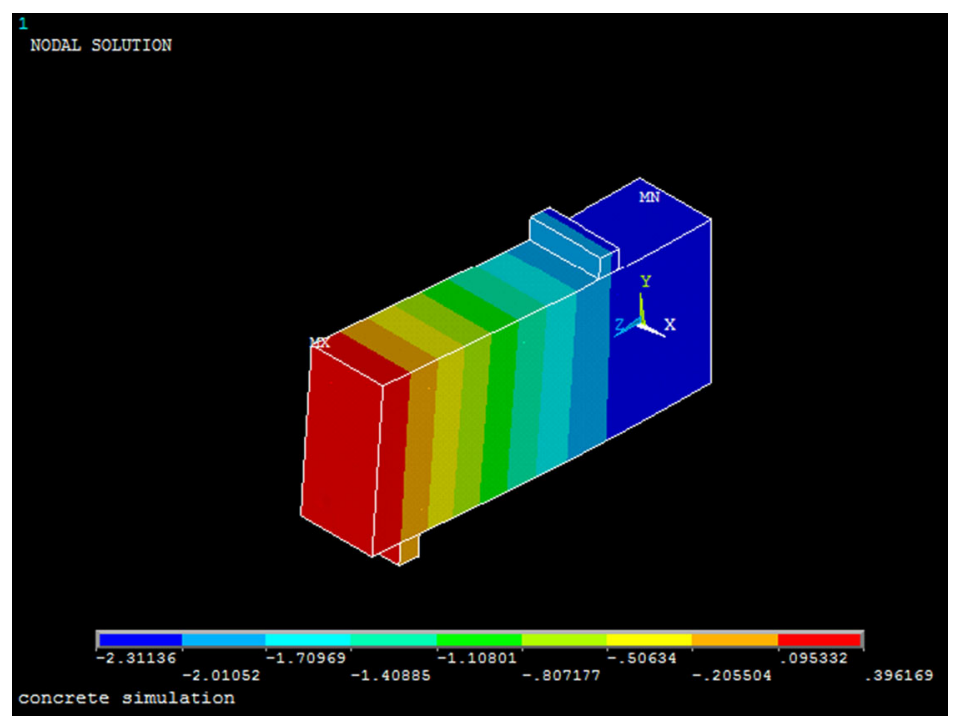

Figure 30. Deflection profile for model 2 of M20 grade of concrete. 
Table 5. Percentage of steel and corresponding E value of RCC (M25).

\begin{tabular}{lcc}
\hline Model no. & Percentage of steel reinforcement $\left(\mathrm{p}_{\mathrm{t}}\right)$ & Modulus of elasticity $\left(\mathrm{N} / \mathrm{mm}^{2}\right)$ \\
\hline 1 & 0.00 & 25994.86 \\
2 & 0.54 & 29161.02 \\
3 & 0.69 & 29502.47 \\
4 & 0.80 & 29716.23 \\
5 & 0.84 & 31438.35 \\
6 & 1.21 & 35510.70 \\
\hline
\end{tabular}

is observed that all the results are in close relationship with each other. First crack pattern is shown in figure 29. The comparison of the crack pattern observed in the experimental results indicated with the ANSYS model zones of critical cracks quite accurately. Figure 30 shows a typical deflection profile for the beam specimen.

All the outcomes are briefed in tables 5, 6 and 7 as shown.

The experimental and analytical data is summarized in tables 7, 8 and 9. It can be observed that the experimental and analytical values are in close relationship with each other. Hence, the results of three more grades of concrete namely M35, M40 and M45 were obtained analytically. These results are used to obtain a generalized equation for modulus of elasticity of RC beam. Eq. (5) is the proposed equation based on regression analysis.

$$
E_{R C C}=3774.23 p_{t}^{2}+2789.67 p_{t}+5000 \sqrt{f_{c k}} .
$$

IS: 456-2000 suggests formula for modulus of elasticity of plain concrete as $\mathrm{E}=5000 \sqrt{f_{c k}}$ which does not consider the effect of reinforcement. It was observed from figures 9, 16 as well as figure 24 that modulus of elasticity of reinforced concrete varies with percentage of reinforcement. The proposed Eq. (5) takes into consideration the effect of concrete grade $f_{c k}$ as well as the percentage of reinforcement $\mathrm{p}_{\mathrm{t}}$.

\section{Conclusions}

- Proposed equation for $E_{R C C}$ in terms of $f_{c k}$ and $p_{t}$ for beam provides sufficient estimate prior analysis of RC structures. As $E_{R C C}$ is more than $E_{P C C}$, deformations as well as structural actions are expected to be on lower side.

Table 6. Percentage of steel and corresponding E value of RCC (M30).

\begin{tabular}{lcc}
\hline Model no. & Percentage of steel reinforcement $\left(\mathrm{p}_{\mathrm{t}}\right)$ & Modulus of elasticity $\left(\mathrm{N} / \mathrm{mm}^{2}\right)$ \\
\hline 1 & 0.00 & 27474.56 \\
2 & 0.54 & 28844.02 \\
3 & 0.69 & 30176.10 \\
4 & 0.80 & 30987.96 \\
5 & 0.84 & 32313.07 \\
6 & 1.21 & 32849.20 \\
7 & 1.63 & 33593.42 \\
\hline
\end{tabular}


Table 7. Experimental and ANSYS results for M20 grade of concrete models.

\begin{tabular}{|c|c|c|c|c|c|c|}
\hline \multirow{2}{*}{$\begin{array}{l}\text { Percentage of steel } \\
\text { reinforcement }\left(\mathrm{p}_{\mathrm{t}}\right)\end{array}$} & \multicolumn{2}{|c|}{ Load $(\mathrm{kN})$} & \multicolumn{2}{|c|}{ Deflection $(\mathrm{mm})$} & \multicolumn{2}{|c|}{ Modulus of elasticity $\left(\mathrm{N} / \mathrm{mm}^{2}\right)$} \\
\hline & Expt. & Analys. & Expt. & Analys. & Expt. & Analys. \\
\hline 0.00 & 68.65 & 65.69 & 1.80 & 1.90 & 24066.80 & 24138.10 \\
\hline 0.54 & 83.00 & 76.48 & 2.00 & 2.33 & 28288.60 & 28087.00 \\
\hline 0.69 & 92.00 & 105.80 & 3.97 & 3.90 & 28453.80 & 27992.50 \\
\hline 0.80 & 95.30 & 101.60 & 3.98 & 4.06 & 31013.40 & 31071.10 \\
\hline 0.84 & 110.40 & 100.70 & 3.97 & 4.00 & 32478.30 & 32538.10 \\
\hline
\end{tabular}

Table 8. Experimental and ANSYS results for M25 grade of concrete models.

\begin{tabular}{|c|c|c|c|c|c|c|}
\hline \multirow{2}{*}{$\begin{array}{l}\text { Percentage of steel } \\
\text { reinforcement (pt) }\end{array}$} & \multicolumn{2}{|c|}{ Load $(\mathrm{kN})$} & \multicolumn{2}{|c|}{ Deflection $(\mathrm{mm})$} & \multicolumn{2}{|c|}{ Modulus of elasticity $\left(\mathrm{N} / \mathrm{mm}^{2}\right)$} \\
\hline & Expt. & Analys. & $\overline{\text { Expt. }}$ & Analys. & Expt. & Analys. \\
\hline 0.00 & 77.40 & 69.31 & 2.08 & 2.00 & 25994.80 & 25265.70 \\
\hline 0.54 & 80.00 & 52.20 & 2.00 & 2.02 & 29161.00 & 29284.40 \\
\hline 0.69 & 90.65 & 85.00 & 3.87 & 3.81 & 29502.40 & 29476.70 \\
\hline 0.80 & 101.00 & 80.07 & 3.81 & 3.80 & 29716.20 & 29790.00 \\
\hline 0.84 & 120.70 & 120.40 & 3.81 & 3.80 & 31483.30 & 31482.10 \\
\hline 1.21 & 144.20 & 135.60 & 4.00 & 4.03 & 35510.70 & 36395.50 \\
\hline
\end{tabular}

Table 9. Experimental and ANSYS results for M30 grade of concrete models.

\begin{tabular}{|c|c|c|c|c|c|c|}
\hline \multirow{2}{*}{$\begin{array}{l}\text { Percentage of steel } \\
\text { reinforcement }\left(\mathrm{p}_{\mathrm{t}}\right)\end{array}$} & \multicolumn{2}{|c|}{ Load $(\mathrm{kN})$} & \multicolumn{2}{|c|}{ Deflection (mm) } & \multicolumn{2}{|c|}{ Modulus of elasticity $\left(\mathrm{N} / \mathrm{mm}^{2}\right)$} \\
\hline & Expt. & Analys. & Expt. & Analys. & Expt. & Analys. \\
\hline 0.00 & 77.40 & 69.31 & 2.08 & 2.00 & 27474.56 & 27543.19 \\
\hline 0.54 & 80.00 & 51.54 & 2.00 & 2.02 & 28844.02 & 29286.29 \\
\hline 0.69 & 98.22 & 124.81 & 3.87 & 3.81 & 30176.10 & 29969.42 \\
\hline 0.80 & 101.09 & 88.39 & 3.81 & 1.16 & 30987.96 & 29780.83 \\
\hline 0.84 & 120.75 & 103.38 & 3.81 & 4.21 & 32313.07 & 31493.56 \\
\hline 1.21 & 90.00 & 87.08 & 2.30 & 2.41 & 32849.20 & 33137.29 \\
\hline 1.63 & 102.34 & 100.14 & 2.40 & 2.53 & 33593.42 & 33600.25 \\
\hline
\end{tabular}

- The range of $\mathrm{p}_{\mathrm{t}}$ in the proposed equation is 0.54 to $1.63 \%$ as per Indian Standard norms for RC beams. This specific range commensurate with geometric parameters of the model analysed.

- Experimental and analytical results fairly match with an error of $\pm 8 \%$.

\section{Acknowledgements}

The experiments were carried out under the research project funded by University of Pune. The authors are thankful to University of Pune for the financial support. The authors also thank Sinhgad College of Engineering, Pune for all the facility to carry out experiments in the laboratory. 


\section{References}

Akmaluddin A and Thomas C 2007 Experimental verification of effective moment of inertia used in the calculation of reinforced concrete beam deflection. Int. Civil Eng. Conference Towards Sustainable Civil Eng. Practice 89-98

Amer M and Huda M M 2009 Finite element modeling of continuous RC beam. Eur. J. Scientific Res. 30(1): 177-186

Amir S, Kent A H and Bahram M S 2013 Crack opening behavior of concrete reinforced with high strength reinforcing steel. Int. J. Concrete Structures and Materials 7(4): 253-264

Antonio F B and Gabriel O R 1998 Analysis of reinforced concrete structures using ansys. Computational Mechanics 1-7

Ghali A 1993 Deflection of reinforced concrete members: A critical review. ACI Structural J. 90(4): 364-373

IS 456:2000 Code of practice for plain and reinforced concrete. New Delhi, India

IS 516:1959 (Reaffirmed 2004) Methods of tests for strength of concrete. New Delhi, India

Khuntia M and Ghosh S K 2004a Flexural stiffness of reinforced concrete columns and beams: Analytical approach. ACI Structural J. 101(3): 351-363

Khuntia M and Ghosh S K 2004b Flexural stiffness of reinforced concrete columns and beams: Experimental verification. ACI Structural J. 101(3): 364-373

Patil S S, Shaikh A N and Niranjan B R 2012 Nonlinear finite element method of analysis of reinforced concrete deep beam. Int. J. Modern Eng. Res. 2(6): 4622-4628

Siddique M A and Rouf M A 2006 Effect of material properties on behaviour of over-reinforced concrete beams. Asian J. Civil Eng. (Building and Housing) 7(2): 195-204

Soroushian P, Sim J and Hsu J W 1991 Axial/Flexural behaviour of reinforced concrete sections: Effects of the design variable. ACI Structural J. 88(1): 17-21

Srikanth M, Kumar R G and Giri S 2007 Moment curvature of reinforced concrete beams using various confinement models and experimental validation. Asian J. Civil Eng. (Building and Housing) 8(3): 247-265

Vasudevan G and Kothandaraman S 2011 Parametric study on Nonlinear Finite Element Analysis on flexural behaviour of RC beams using ANSYS. Int. J. Civil Structural Eng. 2(1): 98-111 